\title{
Evaluation of blood-brain barrier transport and CNS drug metabolism in diseased and control brain after intravenous L-DOPA in a unilateral rat model of Parkinson's disease
}

\author{
Paulien GM Ravenstijn ${ }^{1}$, Henk-Jan Drenth², Michael J O'Neill ${ }^{3}$, Meindert Danhof ${ }^{1}$ and Elizabeth CM de Lange (, $^{4^{*}}$
}

\begin{abstract}
Background: Changes in blood-brain barrier (BBB) functionality have been implicated in Parkinson's disease. This study aimed to investigate BBB transport of L-DOPA transport in conjunction with its intra-brain conversion, in both control and diseased cerebral hemispheres in the unilateral rat rotenone model of Parkinson's disease.

Methods: In Lewis rats, at 14 days after unilateral infusion of rotenone into the medial forebrain bundle, L-DOPA was administered intravenously $(10,25$ or $50 \mathrm{mg} / \mathrm{kg}$ ). Serial blood samples and brain striatal microdialysates were analysed for L-DOPA, and the dopamine metabolites DOPAC and HVA. Ex-vivo brain tissue was analyzed for changes in tyrosine hydroxylase staining as a biomarker for Parkinson's disease severity. Data were analysed by population pharmacokinetic analysis (NONMEM) to compare BBB transport of L-DOPA in conjunction with the conversion of L-DOPA into DOPAC and HVA, in control and diseased cerebral hemisphere.

Results: Plasma pharmacokinetics of L-DOPA could be described by a 3-compartmental model. In rotenone responders (71\%), no difference in L-DOPA BBB transport was found between diseased and control cerebral hemisphere. However, in the diseased compared with the control side, basal microdialysate levels of DOPAC and HVA were substantially lower, whereas following L-DOPA administration their elimination rates were higher.

Conclusions: Parkinson's disease-like pathology, indicated by a huge reduction of tyrosine hydroxylase as well as by substantially reduced levels and higher elimination rates of DOPAC and HVA, does not result in changes in BBB transport of L-DOPA. Taking the results of this study and that of previous ones, it can be concluded that changes in BBB functionality are not a specific characteristic of Parkinson's disease, and cannot account for the decreased benefit of L-DOPA at later stages of Parkinson's disease.
\end{abstract}

Keywords: Population pharmacokinetic modelling, Parkinson's disease, rat rotenone model, BBB transport, L-DOPA, microdialysis

\section{Background}

Tyrosine is usually considered as the starting point in the biosynthesis of dopamine (DA). It is taken up into the brain and subsequently from brain extracellular fluid into dopaminergic neurons where its is converted to 3,4-dihydroxyphenylalanine (L-DOPA), by tyrosine hydroxylase (TH). Aromatic amino acid decarboxylase

\footnotetext{
* Correspondence: l.lange@lacdr.leidenuniv.nl

'Division of Pharmacology, LACDR Leiden University, Leiden, The Netherlands

Full list of author information is available at the end of the article
}

(AADC) then converts L-dopa to DA and stored in vesicles for neurotransmission [1]. Dopamine is metabolized outside the vesicles where monoamine oxidase (MAO) and aldehyde dehydrogenase transform DA into 3,4dihydroxyphenylacetic acid (DOPAC) which then diffuses out of the cells. Subsequently, DOPAC is mainly transformed to homovanillic acid (HVA) by catechol-Omethyltransferase (COMT) [2,3].

It is known that in Parkinson's disease dopaminergic neurons in the nigro-striatal pathway are progressively damaged [4], which causes a decrease in dopamine 
concentration in the striatum. Current therapy for Parkinson's disease focuses mainly on symptomatic treatment to replace the lost dopamine in the striatum. The drug that is routinely used for the symptomatic treatment of Parkinsonism is L-3,4-dihydroxyphenylalanine also known as L-DOPA or levodopa [5]. For patients with early-stage Parkinson's disease, the treatment with L-DOPA is quite successful. However, the benefits of this drug gradually decline in the later stages [4-9]. It may be that this decreased benefit of L-DOPA is solely due to a reduction in the number of viable dopaminergic neurons that can convert L-DOPA into dopamine to reduce the symptoms. However, it may also be that the pharmacokinetics of L-DOPA in the brain for the same dose of L-DOPA may change during disease progression, due to alterations in the functionality of the bloodbrain barrier (BBB) [10].

The question whether the BBB is affected in Parkinson's disease is still a matter of debate. Results from different investigations in animal models or patients with Parkinson's disease vary. Carvey et al. [11] observed areas of BBB leakage in 6-OH-dopamine-treated rats, in an acute model for Parkinson's disease, using FITClabelled albumin and horseradish peroxidase.

Furthermore, they found areas with increased expression of P-glycoprotein (P-gp), and showed that the dopamine antagonist domperidone, that normally has highly limited brain distribution due to its high affinity for P-gp, was able to attenuate apomorphineinduced stereotypic behaviour in these animals. In human positron emission tomography (PET) studies, Bartels et al. found that P-glycoprotein exhibits decreased function in patients with advanced but not early Parkinson's disease [12,13]. The authors suggested that breakdown of the $\mathrm{BBB}$ may occur with increasing severity of the disease. In contrast, in the unilateral rat rotenone model for progressive Parkinson's disease, no changes in $\mathrm{BBB}$ transport were found for fluorescein [14]. Also, in the primate brain, Astradson, et al. [15] found no disruption of the BBB using in vivo neuroimaging techniques with gadolinium-diethylenetriamine pentaacetic acid (Gd-DTPA). With regard to $\mathrm{BBB}$ transport for L-DOPA being dependent on the L-type amino acid influx transporter 1 (LAT1) [16], it is of interest that Ohtsuki et al. [17] found a $\sim 50 \%$ reduction of LAT1 mRNA expression at the $\mathrm{BBB}$ in mice, 7 days after treatment with 1methyl-4-phenyl-1,2,3,6-tetrahydropyridine (MPTP), in conjunction with motor deficits and a loss of dopaminergic neurons. Also, Westin et al. [18] found BBB defects in the basal ganglia in MPTP lesioned/chronic L-DOPA-treated animal models of Parkinson's disease. Finally, Alexander et al. [19] found an inverse relationship between the ability of MPTP-treated monkeys to transport L-DOPA from blood to brain and their degree of Parkinsonism.

Studies on the potential mutual interactions of BBB transport, the fate of L-DOPA metabolism in the brain, and the number of viable dopaminergic neurons under normal and diseased conditions are needed for improved understanding of Parkinson's disease. In this study using a unilateral rat model of Parkinson's disease, we characterized the BBB transport of L-DOPA, L-DOPA's neuropharmacokinetics and its associated conversion, via dopamine, into the main dopamine metabolites DOPAC and HVA, in healthy as well as in late-stage diseased brain. Our hypothesis was that a decrease in BBB transport of L-DOPA would contribute to the decline in LDOPA efficacy at later stages of Parkinson's disease.

In this study, intracerebral microdialysis was used for the determination of BBB transport of L-DOPA [20]. At 14 days after unilateral rotenone infusion into the medial forebrain bundle (MFB), microdialysate samples were collected in parallel with serial blood samples. Concentrations of L-DOPA, dopamine, DOPAC and HVA concentrations were determined in the striatal microdialysis samples, from both the rotenone-infused and the control side. These concentrations were determined under basal conditions as well as following intravenous administration of 10,25 or $50 \mathrm{mg} / \mathrm{kg}$ of L-DOPA. At the end of the experiment, brains were removed for $\mathrm{TH}$ immunostaining to determine responders and non-responders, from the percentage loss of dopaminergic terminals in the striatum. The mutual interactions between the different processes were determined by developing a mathematical model on the basis of the interconnected data obtained.

\section{Methods}

\section{Animals and surgical procedures}

Animals

All animal procedures described in this paper were approved by the Ethical Committee on Animal Experimentation of the University of Leiden (DEC numbers 118 and 5069). Experiments were performed on male Lewis rats (Charles River BV, Maastricht, The Netherlands) weighing $311 \pm 17 \mathrm{~g}$ (mean \pm s.d., $\mathrm{n}=18$ ) and $288 \pm 13$ g (mean \pm s.d., $n=17$ ) before surgery and before start of the experiment, respectively. The rats were housed in standard plastic cages (six per cage before surgery and individually after surgery) with a 12hour day/night schedule (lights on 7:30 a.m.) and at a temperature of $21^{\circ} \mathrm{C}$. The animals had access to standard laboratory chow (RMH-TM; Hope Farms, Woerden, The Netherlands) and acidified water ad libitum.

\section{Surgery}

The surgery for the microdialysis study was performed under anesthesia with an intramuscular injection of 0.1 
$\mathrm{mg} / \mathrm{kg}$ medetomidine hydrochloride (Domitor $1 \mathrm{mg} / \mathrm{ml}$, Pfizer, Capelle a/d IJssel, The Netherlands) and $1 \mathrm{mg} / \mathrm{kg}$ ketamine base (Ketalar $50 \mathrm{mg} / \mathrm{ml}$, Parke-Davis, Hoofddorp, The Netherlands). Three indwelling cannulae (pyrogen-free, nonsterile polyethylene tubing, Portex Limited) were implanted, one in the left femoral artery for blood sampling and two in the left femoral vein for drug administration. The cannulae were tunnelled subcutaneously and fixed at the back of the neck with a rubber ring. The skin in the neck was stitched with normal sutures. The skin in the groin was closed with wound clips. To prevent clotting and obstruction, the cannulae were filled with a $25 \%(\mathrm{w} / \mathrm{v})$ polyvinylpyrrolidone solution (PVP; Brocacef, Maarssen, The Netherlands) in pyrogen-free physiological saline (B. Braun Melsungen AG, Melsungen, Germany) containing 20 $\mathrm{IU} / \mathrm{ml}$ heparin (Hospital Pharmacy, Leiden University Medical Center, Leiden, The Netherlands).

After the implantation of the intravascular cannulae, the rats were placed in a stereotaxic frame and the skull was exposed for brain surgery. The skull was cleaned and a hole was drilled to allow a needle (30 G, Microlance, Becton Dickinson) to be lowered into the right MFB using the co-ordiantes AP: -2.8 ; L: +2.0; V: -9.0 relative to bregma [21] for unilateral infusion of $5.0 \mu \mathrm{g}$ of rotenone (Rotenone Pestanal ${ }^{\circledR}$ Sigma Alldrich BV, Zwijndrecht, the Netherlands) at a rate of $0.1 \mu \mathrm{l} / \mathrm{min}$ for $30 \mathrm{~min}$. Rotenone was dissolved in a 1:1-mixture of dimethylsulfoxide (DMSO, Sigma Alldrich BV) with polyethylene glycol (PEG 200, Sigma Alldrich BV). After the infusion, the needle was kept in place for another 5 min to prevent leakage along the track of the needle. Subsequently, two small holes were drilled into the skull to allow implantation of the microdialysis guide cannulae (CMA/12, Aurora Borealis Control BV, Schoonebeek, The Netherlands) in the left and in the right striatum, AP: $+0.4 ; \mathrm{L}:+/-3.2$; $\mathrm{V}:-3.5$ relative to bregma [21]. One support screw was placed as an extra anchor for the guide, which was glued to the skull with dental acrylic cement (How media simplex rapid + methylacrylate, Drijfhout, Amsterdam, The Netherlands). After surgery, the rats were allowed to recover for 13 days, after which they were randomly assigned to one of three dosing groups of $10 \mathrm{mg} / \mathrm{kg}(\mathrm{n}=4) ; 25 \mathrm{mg} / \mathrm{kg}(\mathrm{n}=4)$; and $50 \mathrm{mg} / \mathrm{kg}(\mathrm{n}=5)$ of L-DOPA. The intracerebral unilateral rat rotenone model used in these experiments, has been described previously by our group [14].

\section{Microdialysis experimental setup}

At 13 days after the unilateral infusion of rotenone into the right MFB, and 18-24 hours prior to the experiment, the microdialysis probes (CMA12, membrane length of $4.0 \mathrm{~mm}$; Aurora Borealis Control BV) were inserted into the guide cannulae. All animals were fasted overnight prior to the experiment in order to rule out any competition in BBB transport of L-DOPA with food-related amino acids [22]. The microdialysis experiment, 14 days post rotenone treatment, was started between 7:00 and 8:00 a.m. The inlets of the microdialysis probes were connected by FEP tubing (fluorinated ethylene propylene tubing; Aurora Borealis Control BV) to syringe pumps (Beehive, Bas Technicol, Congleton, United Kingdom). The probes were perfused with artificial ECF (composition in $\mathrm{mM}: \mathrm{NaCl} 145 ; \mathrm{KCl} 2.7 ; \mathrm{CaCl}_{2}$ 1.2; $\mathrm{MgCl}_{2}$ 1.0; ascorbic acid 0.2 in a $2 \mathrm{mM}$ phosphate buffer $\mathrm{pH}$ 7.4) [23] at a flow rate of $2 \mu \mathrm{l} / \mathrm{min}$. The outlets also consisted of FEP tubing and were connected to a microsample collector (Univentor 820; Antec, Leiden, The Netherlands), in which the samples were cooled ( $4^{\circ}$ C). The vials contained an antioxidant fluid $(0.1 \mathrm{M}$ acetic acid, $3.3 \mathrm{mM}$ L-cysteine, 0.27 M EDTA, 0.0125 $\mathrm{mM}$ ascorbic acid dissolved in Millipore water) in a ratio of 1:4 with the expected volume of the microdialysis sample, to prevent the breakdown of the catecholamines.

After a stabilisation period of $60 \mathrm{~min}$, the in vivo recovery of L-DOPA was determined by the retrodialysis method. For this purpose, the probes were first perfused with a L-DOPA solution $(10,100$ or $200 \mathrm{ng} / \mathrm{ml}$ in the perfusion fluid for the 10,25 and $50 \mathrm{mg} / \mathrm{kg}$ dose groups, respectively) for $60 \mathrm{~min}$ to collect 6 fractions. The relative loss of L-DOPA was determined and used for estimating brain extracellular fluid (brain $\left._{\mathrm{ECF}}\right)$ concentrations. After this period, the syringes were switched to blank perfusion fluid for the washout phase of $90 \mathrm{~min}$.

After the washout period, the intravenous administration of L-DOPA was started. One venous cannula was connected to a syringe containing L-DOPA (Sigma Alldrich BV, Zwijndrecht, the Netherlands) in $0.2 \mathrm{M} \mathrm{HCl}$ in saline $(0.9 \% \mathrm{NaCl})$ and ascorbic acid $(5 \%$ of the $\mathrm{L}$ DOPA amount) and the second venous cannula was connected to a syringe containing $7 \% \mathrm{NaHCO}_{3}$ to neutralize the acidic L-DOPA solution. Both infusions were started at the same time for $20 \mathrm{~min}$ at a rate of $20 \mu \mathrm{l} /$ $\mathrm{min}$. In the first $120 \mathrm{~min}$ of the experiment, microdialysis fractions were collected at 10-min intervals. From 120-180 min, microdialysis fractions were collected at 20 -min intervals. From $180 \mathrm{~min}$ until the end of the experiment (at $360 \mathrm{~min}$ ), microdialysis fractions were collected at 30-min intervals. Blood samples $(50 \mu \mathrm{l}$ in heparinised Eppendorf vials) were taken at pre-dose (5 min before), and at $5,10,15,20,22,24,26,28,30,45$, $50,60,75,90,120,180,240,360 \mathrm{~min}$ after start of the L-DOPA infusion. The blood samples were centrifuged for $10 \mathrm{~min}$ at $5000 \mathrm{rpm}$ and the plasma was pipetted into Eppendorf vials. All samples were stored at $-80^{\circ} \mathrm{C}$ before analysis. After the experiment, the animals were 
given an overdose of sodium pentobarbital (Nembutal, Ceva Santa Animale, Maassluis, The Netherlands) and the thorax was opened and the vascular bed was perfused via the left ventricle of the heart with $30 \mathrm{ml}$ of saline followed by $30 \mathrm{ml}$ of $10 \%$ phosphate buffered formalin $(\mathrm{pH}$ 7.0). Brains were removed for histopathology.

\section{Immunohistopathology}

$\mathrm{TH}$ immunohistochemistry was performed to quantify the degree of dopaminergic depletion as described previously [14]. After staining, striatal sections were analysed by measuring the optical density of manually-defined areas on each black and white image produced as a mean grey value (MGV). Optical density was measured for the slide (background), cortex (control tissue staining), corpus callosum (control non-cellular staining), dorsal striatum (caudate putamen, $\mathrm{CPu}$ ) and ventral striatum (nucleus accumbens, NAcc). The values were adjusted for non-specific staining by subtracting the MGV of the corpus callosum or cortex. Mean, standard deviation and standard error of the mean (sem) of MGV was calculated. All striatal MGV values are corrected for cortical MGV. The percentage of intact $\mathrm{TH}$ staining in the rotenonetreated hemisphere was calculated as the percentage of striatal MGV compared to the striatal MGV of the untreated hemisphere. In the clinical setting, symptoms of Parkinson's disease arise when about $80 \%$ of striatal dopamine and about $60 \%$ of dopamine neurons are lost [4]. The rats which exhibited a $\mathrm{TH}$ staining level lower than $40 \%(60-100 \%$ of the dopamine terminals were lost) were considered as 'responders' to the rotenone treatment.

\section{Analysis of L-DOPA, DOPAC and HVA}

All plasma samples were analysed for L-DOPA and all microdialysate samples were analysed for L-DOPA, dopamine, DOPAC and HVA using a high performance liquid chromatography (HPLC) system with electrochemical detection (ECD).

\section{HPLC and Electrochemical Detection system}

The HPLC system consisted of a LC-10AD HPLC pump (Shimadzu, 's Hertogenbosch, The Netherlands), a Waters 717 Plus autosampler (Waters, Etten-Leur, The Netherlands), a pulse damper (Antec Leyden, Zoeterwoude, The Netherlands) and a digital electrochemical amperometric detector (DECADE, software version 3.02, Antec Leyden). The electrochemical detector consisted of a VT-03 electrochemical flow cell combined with a $25 \mu \mathrm{m}$ spacer and an in situ $\mathrm{Ag} / \mathrm{AgCl}$ (ISAAC) reference electrode operating in the DC mode. For the analysis, a standard $\mathrm{Ag} / \mathrm{AgCl}$ reference electrode, filled with a saturated $\mathrm{KCl}$ solution was used. Data acquisition and processing was performed using the Empower ${ }^{\circledR}$ dataacquisition software (Waters).

\section{Analysis of L-DOPA in plasma}

Chromatography of plasma samples of L-DOPA was performed on a Beckman Coulter ${ }^{\mathrm{TM}}$ Ultrasphere $^{\circledR} 5 \mu \mathrm{m}$ C-18 column (4.6 mm I.D. × $150 \mathrm{~mm}$, Alltech, Breda, The Netherlands) equipped with a refill guard column ( $2 \mathrm{~mm}$ I.D. $\times 20 \mathrm{~mm}$, Upchurch Scientific, Oak Harbor, WA, USA) packed with pellicular C18 material (particle size 20-40 $\mu \mathrm{m}$, Alltech) at a constant temperature of $30^{\circ}$ C. The mobile phase was a mixture of $0.05 \mathrm{M}$ sodium phosphate buffer ( $\mathrm{pH} 2.8$ ) and methanol (90:10, v/v), supplemented with $0.3 \mathrm{mM}$ EDTA (sodium salt) and 10 $\mathrm{mM}$ octane-sulfonic acid. Before the addition of methanol, the mobile phase was filtered through a $0.2 \mu \mathrm{m}$ nylon filter (Alltech), then the methanol was added and it was mixed and degassed with helium. The flow rate was set at $1 \mathrm{~mL} / \mathrm{min}$. The optimal working potential for L-DOPA was $+0.75 \mathrm{~V}$, as determined by a voltammogram and sensitivity plot. Concentrations were measured at a sensitivity range of $5 \mathrm{nA}$ for L-DOPA and $20 \mathrm{nA}$ for 3,4-dihydroxybenzylamine hydrobromide (DHBA; internal standard). Stock solutions of L-DOPA were prepared at a concentration of $1 \mathrm{mg} / \mathrm{mL}$ in Millipore water. The stock solutions were diluted with Millipore water to obtain calibration solutions in the range of 2 to $100 \mathrm{ng} /$ $\mathrm{mL}$. The internal standard (DHBA) solution was prepared by dilution of the stock solution to a final concentration of $500 \mathrm{ng} / \mathrm{mL}$. The stock solutions were stored at $-80^{\circ} \mathrm{C}$ for up to one month. The assay solutions were prepared freshly before each analysis. For determination of the L-DOPA in plasma, $25 \mu \mathrm{L}$ of internal standard solution (DHBA $500 \mathrm{ng} / \mathrm{mL}$ ) was added to $45 \mu \mathrm{L}$ plasma samples and $50 \mu \mathrm{L}$ of Millipore water in glass centrifuge tubes. Next, $25 \mu \mathrm{L}$ of $20 \%$ TCA was added and the mixture was vortexed for $5 \mathrm{~min}$. After centrifugation for 10 $\min$ at $4000 \mathrm{rpm}(2000 \mathrm{~g}), 100 \mu \mathrm{L}$ of the supernatant was added to $50 \mu \mathrm{L}$ of phosphoric buffer ( $1 \mathrm{M}, \mathrm{pH} 5.5)$ of which $25 \mu \mathrm{L}$ was injected into the HPLC system.

\section{Analysis of L-DOPA, dopamine, DOPAC and HVA in microdialysate}

For analysis of L-DOPA, dopamine, DOPAC and HVA brain microdialysate concentrations, $5 \mu \mathrm{L}$ of internal standard (isoproterenol, $100 \mathrm{ng} / \mathrm{mL}$ ) solution was added per $10 \mu \mathrm{L}$ of microdialysis sample or calibration curve sample. The samples were then injected $(20 \mu \mathrm{L})$ into the HPLC system without further sample pre-treatment. Chromatography of brain microdialysate samples was performed on a Beckman Coulter ${ }^{\mathrm{TM}}$ Ultrasphere $^{\circledR} 5 \mu \mathrm{m}$ C-18 column ( $2 \mathrm{~mm}$ I.D. $\times 250 \mathrm{~mm}$, Alltech) at a constant temperature of $30^{\circ} \mathrm{C}$. The mobile phase was a mixture of $0.05 \mathrm{M}$ sodium phosphate buffer ( $\mathrm{pH} 2.8$ ) and methanol $(88: 12, \mathrm{v} / \mathrm{v})$, supplemented with $0.3 \mathrm{mM}$ EDTA (sodium salt) and $1.5 \mathrm{mM}$ octane-sulfonic acid. 
Mobile phase solvents were filtered through a $0.2 \mu \mathrm{m}$ nylon filter. The methanol was added and the mobile phase was mixed and degassed with helium. The flow rate was set at $0.2 \mathrm{~mL} / \mathrm{min}$. The optimal working potential for a mixture of L-DOPA, dopamine, DOPAC and HVA was $+0.66 \mathrm{~V}$, as determined by a voltammogram and sensitivity plot. Concentrations were measured at a sensitivity range of: $0.1 \mathrm{nA}$ for dopamine, $0.5 \mathrm{nA}$ for LDOPA, HVA and isoproterenol; and $10 \mathrm{nA}$ for DOPAC. For analysis of brain microdialysate samples, stock solutions of L-DOPA, DOPAC and HVA were prepared at a concentration of $0.5 \mu \mathrm{g} / \mathrm{mL}$ for dopamine, $1 \mu \mathrm{g} / \mathrm{mL}$ for L-DOPA and $5 \mu \mathrm{g} / \mathrm{mL}$ for DOPAC and HVA in microdialysis perfusion fluid with aqueous antioxidant solution consisting of $0.1 \mathrm{M}$ acetic acid, $3.3 \mathrm{mM}$ L-cysteine, $0.27 \mathrm{M}$ EDTA (sodium salt) and $0.0125 \mathrm{mM}$ ascorbic acid $(4: 1 \mathrm{v} / \mathrm{v})$. Internal standard solution was freshly prepared before each analysis by dilution of a $1 \mathrm{mg} / \mathrm{mL}$ isoproterenol stock solution, to a concentration of $100 \mathrm{ng} /$ $\mathrm{mL}$ of the compound in perfusion fluid that contains antioxidant $(4: 1 \mathrm{v} / \mathrm{v})$. All the stock solutions were stored at $-80^{\circ} \mathrm{C}$ for up to one month. Before each analysis a first calibration solution containing all compounds was freshly prepared by mixing one volume of each stock solution (L-DOPA, dopamine, DOPAC and HVA) and adding 5 volumes of perfusion fluid with antioxidant $(6: 1 \mathrm{v} / \mathrm{v})$. This first calibration solution now contained all compounds at a concentration 10 times lower than their stock solution and from this solution the other calibration solutions were prepared.

\section{Population pharmacokinetic data analysis- model development}

The pharmacokinetics of L-DOPA, DOPAC and HVA were analysed utilizing a population pharmacokinetic modelling approach. Dopamine concentrations were all below the limit of detection. Compartmental modelling was performed using the ADVAN6 subroutine in NONMEM VI release 2 (GloboMax LLC, Hanover, MD, USA). All fitting procedures were performed on an IBM-compatible computer (Pentium IV, $1500 \mathrm{MHz}$ ) running under Windows XP with the Compaq Visual Fortran compiler version 6.6. The inter-individual variability of model parameters was described by an exponential equation, according to:

$$
\mathrm{P}_{1 \mathrm{i}}=\theta_{1} \cdot \exp \left(\eta_{\mathrm{i}}\right)
$$

where $\theta_{1}$ is the population (typical) estimate for parameter $\mathrm{P}_{1}, \mathrm{P}_{1 \mathrm{i}}$ is the individual estimate and $\eta_{\mathrm{i}}$ determines the random deviation of $\mathrm{P}_{1 \mathrm{i}}$ from $\mathrm{P}_{1}$. The values of $\eta_{i}$ are assumed to be randomly, normally distributed with mean zero and variance $\omega_{11}{ }^{2}$. The residual error in the L-DOPA concentration was described by a proportional error model:

$$
\mathrm{C}_{\mathrm{obs}, \mathrm{ij}}=\mathrm{C}_{\text {pred, }, \mathrm{ij}} \cdot\left(1+\varepsilon_{\mathrm{ij}}\right),
$$

and the residual error in the DOPAC or HVA concentration was described by an additive error model:

$$
\mathrm{C}_{\mathrm{obs}, \mathrm{ij}}=\mathrm{C}_{\text {pred }, \mathrm{ij}}+\varepsilon_{\mathrm{ij}}
$$

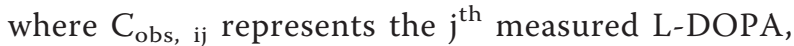
DOPAC or HVA concentration for the $\mathrm{i}^{\text {th }}$ individual predicted by the model. $C_{\text {pred, ij }}$ represents the prediction of concentration and $\varepsilon_{i j}$ is the deviation of the model-predicted value from the observed concentration. The values of $\varepsilon$ are assumed to be randomly, normally distributed with mean zero and variance $\sigma^{2}$.

The first order conditional estimation method with interaction (FOCE interaction) was used in NONMEM to fit the models to the data and to estimate $\theta^{\prime} s, \omega^{2}$ 's and $\sigma^{2}$ s. Structural model selection for all models was based on the likelihood ratio test, diagnostic plots (observed concentrations vs. individual and population predicted concentrations, conditional weighted residuals vs. time and predicted concentrations), parameter correlations and precision in parameter estimates. Inclusion of one parameter into the model was assumed to be significant if this led to a decrease of 10.8 points or more of the minimum value of the objective function (MVOF) after fitting the model to the data. This corresponds to a theoretical significance level of $p=0.001$ under the assumption that the difference in MVOF between two nested models is $\chi^{2}$ distributed.

In total, the L-DOPA plasma profiles of 13 rats (10 $\mathrm{mg} / \mathrm{kg}, \mathrm{n}=4 ; 25 \mathrm{mg} / \mathrm{kg}, \mathrm{n}=4 ; 50 \mathrm{mg} / \mathrm{kg}, \mathrm{n}=5$ ), the L-

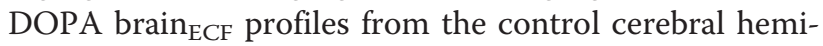
sphere of 12 rats $(10 \mathrm{mg} / \mathrm{kg}, \mathrm{n}=4 ; 25 \mathrm{mg} / \mathrm{kg}, \mathrm{n}=3 ; 50$ $\mathrm{mg} / \mathrm{kg}, \mathrm{n}=5$ ) and the L-DOPA brain ECF $_{\text {profiles from }}$ the rotenone-treated responder cerebral hemisphere of 7 responder rats $(10 \mathrm{mg} / \mathrm{kg}, \mathrm{n}=1 ; 25 \mathrm{mg} / \mathrm{kg}, \mathrm{n}=2 ; 50$ $\mathrm{mg} / \mathrm{kg}, \mathrm{n}=4$ ) were included in the population pharmacokinetic analysis.

On the basis of selection criteria, the plasma and brai$\mathrm{n}_{\mathrm{ECF}}$ L-DOPA data from the individual rats were simultaneously analysed (Figure 1; compartments 1-5). First, clearances from compartment 1 to 4 (Cl14), compartment 4 to 1 (Cl41), compartment 1 to $5(\mathrm{Cl} 15)$ and compartment 5 to $1(\mathrm{Cl} 51)$ were assigned in the structural model to seek for concentration-dependent BBB transport of L-DOPA via the LAT-1 transporter. However, although a large range of plasma concentration data was available (3 dosages of L-DOPA), no asymmetry in BBB transport could be identified. The model was therefore simplified to use the inter-compartmental clearances Q4 and Q5. 


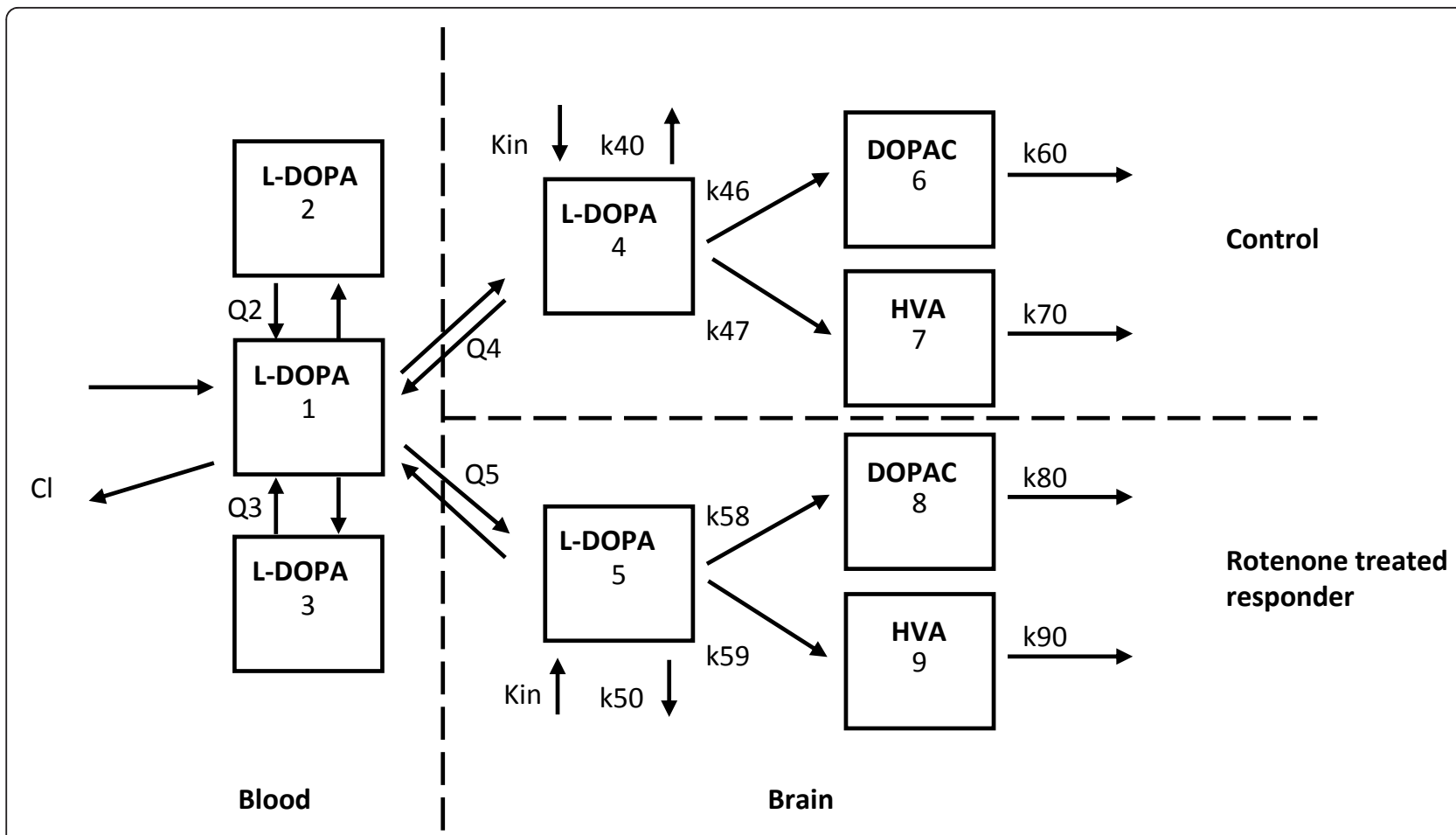

Figure 1 The population pharmacokinetic model for L-DOPA, DOPAC and HVA comprising of three compartments (1-3) describing the pharmacokinetics of L-DOPA in plasma, two compartments (4 and 5) describing the pharmacokinetics of L-DOPA in brain ${ }_{E C F}$, one for the control cerebral hemisphere and one for the rotenone-treated responder cerebral hemisphere, two compartments (6 and 8 ) describing the kinetics of DOPAC in brain $_{\mathrm{ECF}}$, one for the control cerebral hemisphere and one for the rotenone-treated responder cerebral hemisphere and two compartments (7 and 9) describing the kinetics of HVA in brain ${ }_{E C F}$, one for the control cerebral hemisphere and one for the rotenone-treated responder cerebral hemisphere. $(V=$ volume of distribution, $Q=$ inter-compartmental clearance, $\mathrm{k}=$ elimination rate constant, $\mathrm{Kin}=$ endogenous formation rate constant of L-DOPA.).

Individual model parameters (post hoc estimates) for each rat from this analysis and typical values from this model (Table 1) were then used as input for the subsequent analysis of DOPAC (Figure 1; compartments 6 and 8) and HVA (Figure 1; compartments 7 and 9). In total, the DOPAC and HVA microdialysate concentrations obtained from the control cerebral hemisphere of 12 rats $(10 \mathrm{mg} / \mathrm{kg}: \mathrm{n}=4 ; 25 \mathrm{mg} / \mathrm{kg}: \mathrm{n}=3 ; 50 \mathrm{mg} / \mathrm{kg}: \mathrm{n}$ = 5) and the DOPAC and HVA microdialysate concentrations from the rotenone-treated responder cerebral hemisphere of 8 rats $(10 \mathrm{mg} / \mathrm{kg}: \mathrm{n}=2 ; 25 \mathrm{mg} / \mathrm{kg}: \mathrm{n}=2$; $50 \mathrm{mg} / \mathrm{kg}: \mathrm{n}=4$ ) were included in the population pharmacokinetic analysis.

\section{Results}

The percentage of intact $\mathrm{TH}$ staining in the rotenonetreated cerebral hemisphere compared to the untreated hemisphere at the level of the striatum was below $40 \%$ in 12 out of 17 rats (responders), and higher than $90 \%$ in the remaining 5 rats (non-responders). No quantifiable concentrations of dopamine could be detected throughout the experiment (limit of quantification was $0.01 \mathrm{ng} / \mathrm{mL}$ in a $20 \mu \mathrm{l}$ microdialysate sample). A total of
17 rats were used in the microdialysis experiments: $\mathrm{n}=$ 6 in the 10 - and $25 \mathrm{mg} / \mathrm{kg}$ dose group and $\mathrm{n}=5$ in the $50 \mathrm{mg} / \mathrm{kg}$ dose group, where for one rat the microdialysis probe malfunctioned. All microdialysate concentrations of L-DOPA were corrected for the average in vivo recovery as determined during the retrodialysis period $(30 \pm 6 \%)$ in order to estimate brain ${ }_{\mathrm{ECF}}$ concentrations. The in vivo recovery was equal for the three concentrations of L-DOPA used, and not affected by disease condition.

\section{Data analysis \\ L-DOPA pharmacokinetic modeling}

The plasma concentration-time profiles for each rat following intravenous infusion of 10,25 , and $50 \mathrm{mg} / \mathrm{kg}$ of L-DOPA are shown in Figure 2. The resulting brain ${ }_{\mathrm{ECF}}$ concentration-time profiles of L-DOPA are shown in Figure 3, for both the control and the responder cerebral hemispheres. The L-DOPA concentrations in plasma and in brain ${ }_{E C F}$ were analysed simultaneously. All structural parameters of the population pharmacokinetic model for L-DOPA could be adequately estimated (Table 1). No dose-dependency was observed in the 
Table 1 Population pharmacokinetic parameter estimates with the corresponding inter-individual coefficient of variation (CV\%) and lower -and upper limit confidence intervals ( $\mathrm{LLCl}$ and $\mathrm{ULCl}$ ).

\begin{tabular}{|c|c|c|c|}
\hline Parameter & Estimate & CV\% & LLCI-ULCI \\
\hline \multicolumn{4}{|l|}{ L-DOPA } \\
\hline $\mathrm{Cl}(\mathrm{mL} / \mathrm{min})$ & 30 & 21 & $17-43$ \\
\hline$\omega^{2} \mathrm{Cl}$ & 0.26 & 59 & $-0.041-0.56$ \\
\hline V1 (mL) & 98 & 39 & $24-172$ \\
\hline V2 (mL) & 157 & 15 & $112-202$ \\
\hline V3 (mL) & 599 & 15 & $425-773$ \\
\hline V4 (mL) & 13300 & 25 & $6810-19800$ \\
\hline$\omega^{2} \vee 4$ & 0.075 & 40 & $0.020-0.13$ \\
\hline Q2 (mL/min) & 22 & 24 & $11-32$ \\
\hline Q3 (mL/min) & 11 & 16 & $7.5-15$ \\
\hline Q4 (mL/min) & 22 & 14 & $16-29$ \\
\hline$K_{\text {in }}\left(\min ^{-1}\right)$ & 5.8 & 36 & $1.7-9.8$ \\
\hline$\omega^{2} K_{\text {in }}$ & 0.94 & 41 & $0.19-1.7$ \\
\hline Proportional error (plasma) & 0.087 & 15 & $0.061-0.113$ \\
\hline Proportional error (ECF) & 0.17 & 21 & $0.10-0.24$ \\
\hline \multicolumn{4}{|l|}{ Control cerebral hemisphere } \\
\hline \multicolumn{4}{|l|}{ DOPAC } \\
\hline Formation k46 $\left(\mathrm{min}^{-1}\right)$ & 0.000044 & 28 & $0.000020-0.000068$ \\
\hline$\omega^{2} \mathrm{k} 46$ & 0.50 & 60 & $-0.084-1.1$ \\
\hline $\mathrm{k} 40\left(\mathrm{~min}^{-1}\right)$ & 0.53 & 23 & $0.29-0.77$ \\
\hline$\omega^{2} k 40$ & 0.42 & 46 & $0.045-0.80$ \\
\hline Elimination $\mathrm{k} 60\left(\mathrm{~min}^{-1}\right)$ & 0.0053 & 17 & $0.0035-0.0071$ \\
\hline$\omega^{2} \mathrm{k} 60$ & 0.19 & 58 & $-0.025-0.41$ \\
\hline Residual error (additive) & 0.0020 & 16 & $0.0014-0.0026$ \\
\hline \multicolumn{4}{|l|}{ HVA } \\
\hline Formation k47 $\left(\mathrm{min}^{-1}\right)$ & 0.000023 & 15 & $0.000016-0.000030$ \\
\hline$\omega^{2} \mathrm{k} 47$ & 0.019 & 70 & $-0.0070-0.000030$ \\
\hline $\mathrm{k} 40\left(\mathrm{~min}^{-1}\right)$ & 0.19 & 16 & $0.13-0.25$ \\
\hline k70 $\left(\min ^{-1}\right)$ & 0.0044 & 12 & $0.0033-0.0054$ \\
\hline$\omega^{2} k 70$ & 0.14 & 53 & $-0.006-0.28$ \\
\hline Residual error (additive) & 0.0028 & 24 & $0.0015-0.0041$ \\
\hline
\end{tabular}

Rotenone-treated responder cerebral

hemisphere

DOPAC

\begin{tabular}{llll}
\hline Formation $\mathrm{k} 58\left(\mathrm{~min}^{-1}\right)$ & 0.000054 & 51 & $-0.00000039-0.000011$ \\
$\omega^{2} \mathrm{k} 58$ & 1.0 & 40 & $0.23-1.9$ \\
$\mathrm{k} 50\left(\mathrm{~min}^{-1}\right)$ & 0.36 & 55 & $-0.025-0.75$ \\
$\omega^{2} \mathrm{k} 50$ & 0.53 & 36 & $0.16-0.90$ \\
Elimination k80 $\left(\mathrm{min}^{-1}\right)$ & 0.038 & 18 & $0.024-0.052$ \\
Residual error (additive) & 0.0014 & 51 & $0.0000020-0.0027$ \\
\hline HVA & & & \\
\hline Formation k59 $\left(\mathrm{min}^{-1}\right)$ & 0.000016 & 42 & $0.0000028-0.000030$ \\
$\omega^{2} \mathrm{k} 59$ & 0.49 & 65 & $-0.14-1.12$ \\
k50(min & \\
Elimination $\mathrm{k90}\left(\mathrm{min}^{-1}\right)$ & 0.14 & 55 & $-0.010-0.29$ \\
Residual error (additive) & 0.011 & 39 & $0.0027-0.020$ \\
\hline
\end{tabular}

$\mathrm{V}=$ volume of distribution, $\mathrm{Q}=$ inter-compartmental clearance, $\mathrm{k}=$ elimination rate constant. Note: $\mathrm{V} 5=\mathrm{V} 4, \mathrm{Q} 5=\mathrm{Q} 4$ and $\mathrm{k} 50=\mathrm{k} 40$. plasma pharmacokinetics for L-DOPA. No significant difference could be detected between the inter-compartmental clearances Q4 and Q5, the volumes of distribution V4 and V5 or the elimination rate constants $\mathrm{k} 40$ and $\mathrm{k} 50$ when these models were fitted to the L-DOPA brain concentration data. Table 2 shows a summary of the MVOF and parameter estimates after the different assumptions $(\mathrm{Q} 4=\mathrm{Q} 5, \mathrm{~V} 4=\mathrm{V} 5, \mathrm{k} 40=\mathrm{k} 50$ or a combination of any of these). Also, the separate estimate of endogenous brain production rate of L-DOPA $\left(K_{\text {in }}\right)$ for compartment 4 and 5 resulted in similar estimated

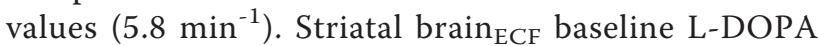
levels in the rotenone-treated responder cerebral hemisphere were not statistically different $(p=0.07$; Welch's t-test) from those in the control hemisphere and averaged $0.010 \pm 0.004 \mathrm{pmol} / \mathrm{mL}$ and $0.024 \pm 0.011 \mathrm{pmol} /$ $\mathrm{mL}$ (mean $\pm \mathrm{SEM}$ ), respectively. Therefore, it can be concluded that no significant difference can be identified between the pharmacokinetics of L-DOPA in the control versus the rotenone-treated responder cerebral hemisphere.

\section{DOPAC and HVA kinetic modeling}

Striatal microdialysate baseline DOPAC levels in the rotenone-treated responder cerebral hemisphere were about 6 times lower than in the control cerebral hemisphere and averaged $0.2 \pm 0.19 \mathrm{pmol} / \mathrm{mL}$ and $1.3 \pm 0.17$ $\mathrm{pmol} / \mathrm{mL}$ (mean $\pm \mathrm{SEM})$, respectively ( $p$-value $<0.01$; Welch's t-test). Also, striatal microdialysate baseline HVA dialysate levels in the rotenone-treated responder cerebral hemisphere were lower (approximately 4 times) than in the control cerebral hemisphere with respective values of $0.25 \pm 0.14 \mathrm{pmol} / \mathrm{mL}$ and $0.9 \pm 0.08 \mathrm{pmol} / \mathrm{mL}$ (mean \pm SEM), respectively ( $p$-value $=0.02$; Welch's $\mathrm{t}$ test). Figure 4 shows the population predicted microdialysate concentrations of DOPAC and HVA versus time for a typical rat per dose group. All structural parameters of the population kinetic model for DOPAC as well as for HVA could be adequately estimated (Table 1 ). No dose-dependency was found in any of the parameters for DOPAC or HVA. For DOPAC, k46 and k58 (rate constants which describe the conversion of LDOPA, via dopamine, to DOPAC) do not significantly differ, which means that there appears to be no effect of disease on the metabolism of L-DOPA via dopamine to DOPAC. The same can be said for HVA for which k47 and k59 do not significantly differ. On the other hand, the elimination rate constants were found to be 7 -fold and 2.5-fold higher in the rotenone-treated responder compared to the control side for DOPAC ( 660 and $k 80$ ) and HVA (k70 and k90), respectively.

\section{Discussion}

In this study using the rotenone-treated rat as a model for Parkinson's disease, the relationship between plasma and 


\section{0}

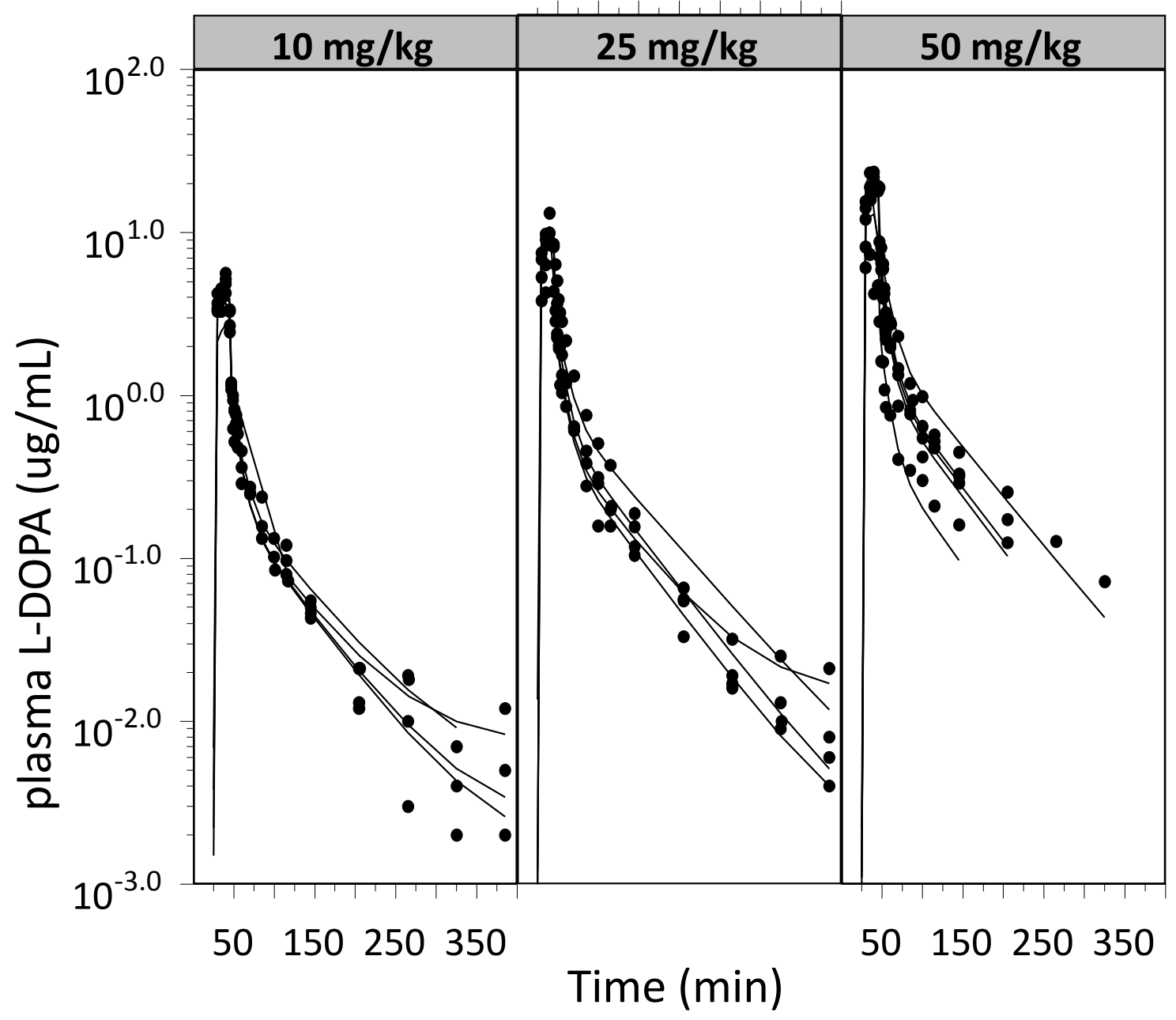

Figure 2 L-DOPA concentration-time profiles in plasma, obtained after a 20-min intravenous infusion in Lewis rats. Depicted are the observed concentrations (dots) and individual predictions (solid lines), separated by L-DOPA dose (in total 13 rats: $10 \mathrm{mg} / \mathrm{kg}, \mathrm{n}=4 ; 25 \mathrm{mg} / \mathrm{kg}, \mathrm{n}$ $=4 ; 50 \mathrm{mg} / \mathrm{kg}, \mathrm{n}=5$ ).

brain $_{\mathrm{ECF}}$ pharmacokinetics (BBB transport) of L-DOPA and its conversion into the dopamine metabolites DOPAC and HVA, was measured in parallel in the rotenone-treated responder and control cerebral hemisphere at 14 days post-rotenone injection. NONMEM was used to develop a population based pharmacokinetic model. Basal concentrations of DOPAC and HVA in striatal microdialysate were lower in the rotenone-treated responder brain than in the control brain. Furthermore, it was shown that disease-related changes were observed in the kinetics of the dopamine metabolites following L-DOPA administration, without any changes in BBB transport of L-DOPA.

In our study, following the rotenone infusion in the MFB of the rats, the Parkinson's disease state was defined as TH immunostaining in the striatum with a density of less than $40 \%$ of control values (termed responders). Data indicated that the number of responders in this model was similar to our previous study [14], and the disease pathology was successfully induced in $70 \%$ of the rats. It would be of interest to have more information on potential changes in the pharmacokinetics, BBB transport and conversion of L-DOPA at different stages of Parkinson's disease. In this study the $\mathrm{TH} \%$ values found at 14 days following rotenone treatment were either close to $100 \%$ (non-responders) or smaller than $40 \%$ (responders; Figure 5), leaving too small a range to investigate the $\mathrm{TH} \%$ as a covariate in the model. A shorter interval between rotenone treatment and experiment might have resulted in more diverse values for $\mathrm{TH} \%$. 


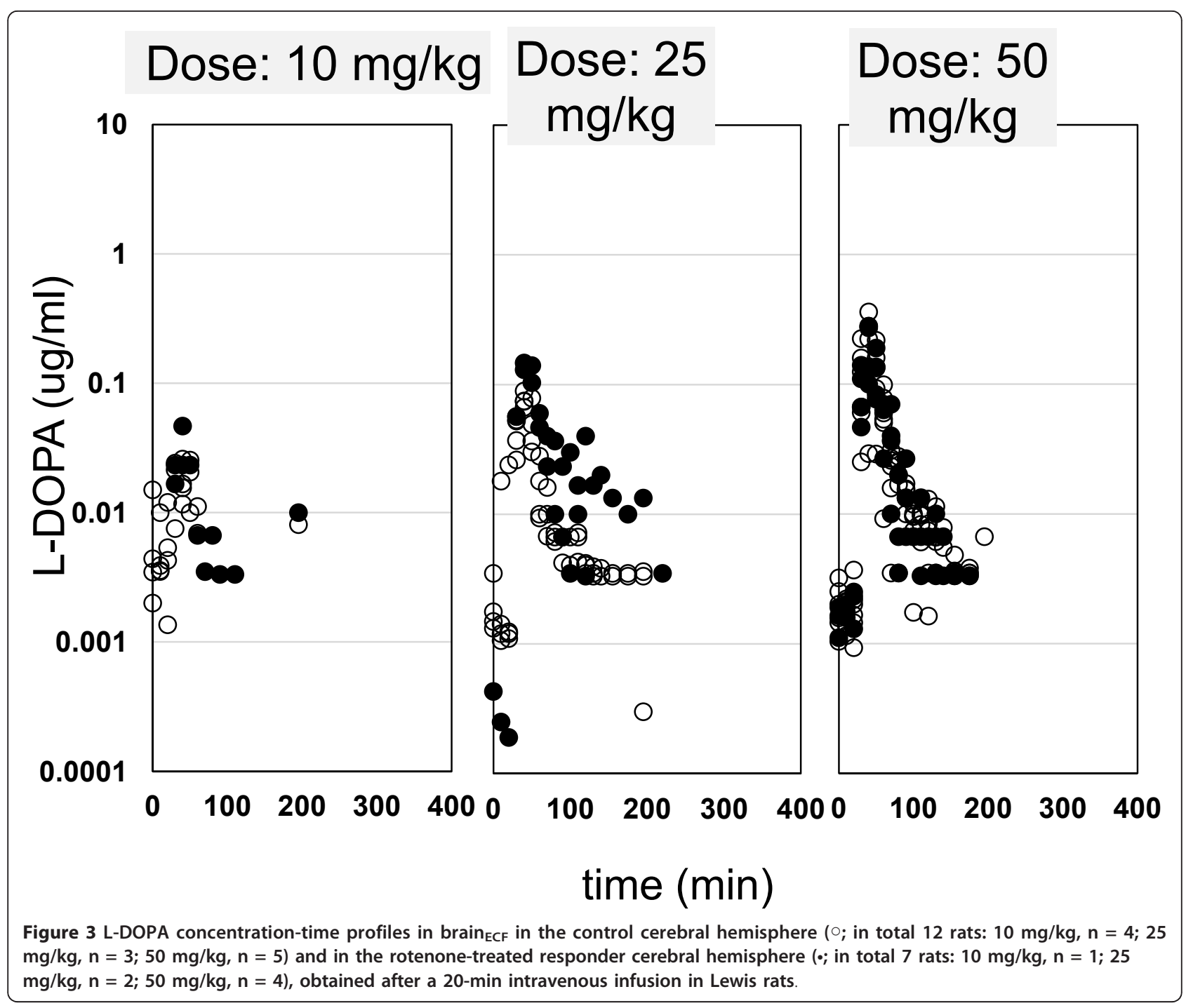

\section{L-DOPA kinetics in plasma}

The results described in this paper are the first in which

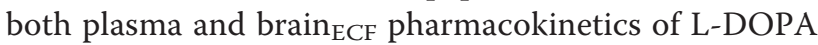
in control and rotenone-treated conditions are described by a population pharmacokinetic model. The pharmacokinetics of L-DOPA in plasma following intravenous administration was best described by a three-compartmental model, like previously reported [24]. In our study, we were not able to measure endogenous plasma concentrations of L-DOPA (LLQ was $1 \mathrm{ng} / \mathrm{mL}$ ). Sato et al. [25] found in their rat study a basal level of $2.1 \pm 0.6 \mathrm{mg} / \mathrm{L}$. In our study, rats were fasted overnight which might be the reason for much lower endogenous L-DOPA in plasma. The total clearance of exogenous plasma of L-DOPA in the study by Sato et al. [26] was $3.1 \mathrm{~L} / \mathrm{h} / \mathrm{kg}$, which is in the same order of magnitude as our value of $6.3 \mathrm{~L} / \mathrm{h} / \mathrm{kg}(\mathrm{Cl}=30 \mathrm{~mL} / \mathrm{min}$, Table 1; mean weight of the rats before start of the experiment was $288 \pm 13 \mathrm{~g}$ ).

\section{L-DOPA BBB transport}

No difference in BBB transport of L-DOPA between the control and rotenone-treated responder cerebral hemisphere were found. This is in contrast to the findings of an inverse relationship between the MPTP-monkeys' ability to transport L-DOPA from blood to brain and their degree of Parkinsonism by Alexander et al. [19]. This may be due to species differences as well as differences in the disease conditions.

\section{L-DOPA endogenous kinetics}

Also, our results did not indicate a disease-induced change in the endogenous production of L-DOPA in the brain (Kin; $5.8 \mathrm{~min}^{-1}$ ). Since dopamine-producing neurons are diminished in Parkinson's disease [4], one would expect a decrease in the endogenous concentration of L-DOPA, as it is a product of the metabolism of L-tyrosine by $\mathrm{TH}$. However, it has been reported that 
Table 2 Summary of goodness-of-fit based on the minimum value of objective function (MVOF), of eight assumptions within the modeling of L-DOPA in plasma and brain ECF.

\begin{tabular}{|c|c|c|c|c|c|c|c|c|}
\hline Assumption & Results & MVOF & V4 & V5 & Q4 & Q5 & $\mathrm{K} 40$ & K50 \\
\hline \multirow[t]{3}{*}{ NONE } & general & -2814 & 11100 & 16100 & 20,9 & 25,3 & 0,211 & 0,135 \\
\hline & SE & & 3840 & 6970 & 3,74 & 9,24 & 0,033 & 0,0132 \\
\hline & $\mathrm{CV}(\%)$ & & 34,6 & 43,3 & 17,9 & 36,5 & 15,6 & 9,78 \\
\hline \multirow[t]{3}{*}{$\mathrm{V} 5=\mathrm{V} 4$} & general & -2808 & 12700 & & 22,9 & 20,1 & 0,193 & 0,161 \\
\hline & SE & & 5700 & & 4,33 & 7,13 & 0,0329 & 0,0185 \\
\hline & $\mathrm{CV}(\%)$ & & 44,9 & & 18,9 & 35,5 & 17 & 11,5 \\
\hline \multirow[t]{3}{*}{$k 50=k 40$} & general & -2803 & 13200 & 12000 & 20,1 & 26 & 0,175 & \\
\hline & SE & & 3870 & 4990 & 3,36 & 8,77 & 0,0226 & \\
\hline & $\mathrm{CV}(\%)$ & & 29,3 & 41,6 & 16,7 & 33,7 & 12,9 & \\
\hline \multirow[t]{3}{*}{$\mathrm{Q} 5=\mathrm{Q} 4$} & general & -2813 & 11400 & 14400 & 22 & & 0,211 & 0,135 \\
\hline & SE & & 3080 & 3700 & 3,18 & & 0,027 & 0,0127 \\
\hline & $\mathrm{CV}(\%)$ & & 27 & 25,7 & 14,5 & & 12,8 & 9,41 \\
\hline \multirow[t]{3}{*}{$\mathrm{V} 5=\mathrm{V} 4 \mathrm{\&} \mathrm{k} 50=\mathrm{k} 40$} & general & -2804 & 13000 & & 21,4 & 24,3 & 0,179 & \\
\hline & SE & & 3410 & & 3,2 & 5,56 & 0,0199 & \\
\hline & $C V(\%)$ & & 26,2 & & 15 & 22,9 & 11,1 & \\
\hline \multirow[t]{3}{*}{$\mathrm{V} 5=\mathrm{V} 4 \& \mathrm{Q} 5=\mathrm{Q} 4$} & general & m.t. & 13000 & & 22 & & 0,19 & 0,17 \\
\hline & SE & & - & - & - & - & - & - \\
\hline & $\mathrm{CV}(\%)$ & & - & - & - & - & - & - \\
\hline \multirow[t]{3}{*}{$\mathrm{k} 50=\mathrm{k} 40 \& \mathrm{Q} 5=\mathrm{Q} 4$} & general & -2801 & 13900 & 10600 & 21,7 & & 0,173 & \\
\hline & SE & & 8290 & 6610 & 7,79 & & 0,0276 & \\
\hline & $\mathrm{CV}(\%)$ & & 59,6 & 62,4 & 35,9 & & 16 & \\
\hline \multirow[t]{3}{*}{$\mathrm{V} 5=\mathrm{V} 4 \& \mathrm{k} 50=\mathrm{k} 40 \& \mathrm{Q} 5=\mathrm{Q} 4$} & general & -2801 & 13300 & & 22,4 & & 0,175 & \\
\hline & SE & & 3310 & & 3,17 & & 0,0201 & \\
\hline & CV(\%) & & 24,9 & & 14,2 & & 11,5 & \\
\hline
\end{tabular}

The assumption 'NONE' is where all parameters were estimated.

$\mathrm{V}=$ volume of distribution, $\mathrm{Q}=$ inter-compartmental clearance, $\mathrm{k}=$ elimination rate constant

TH enzyme activity, as a function of the degree of dopamine loss, is up-regulated in the striatum of 6-OHDAlesioned rats and of MPTP-treated rhesus monkeys [27]. This phenomenon was assumed to be a compensatory mechanism of the remaining dopaminergic neurons triggered by the synaptic dopamine loss [28]. It may as well be the case in our situation that up-regulation of $\mathrm{TH}$ in the rotenone-treated responder brain is the reason for the absence of disease-induced changes in L-DOPA concentrations in the brain.

\section{L-DOPA brain metabolism to DOPAC and HVA}

The main metabolite of L-DOPA in the early phase after drug administration is dopamine [29,30], which is further metabolized to mainly DOPAC and HVA. The metabolism of L-DOPA via dopamine to DOPAC in the control cerebral hemisphere $\left(0.000044 \mathrm{~min}^{-1}\right)$ was indistinguishable from that of the rotenone-treated responder brain $\left(0.000054 \mathrm{~min}^{-1}\right)$. Also, the metabolism of $\mathrm{L}-$ DOPA via dopamine to HVA in the untreated brain $\left(0.000023 \mathrm{~min}^{-1}\right)$ was similar to that in the rotenonetreated responder cerebral hemisphere $\left(0.000016 \mathrm{~min}^{-1}\right)$. Furthermore, these values reflect a slow conversion of
L-DOPA-via dopamine- to these metabolites. Overall, in contrast to our expectations, it can be said that the disease conditions at 2 weeks post-rotenone-injection into the MFB did not result in any change in the pharmacokinetics of L-DOPA.

\section{Baseline DOPAC and HVA}

The baseline concentrations of DOPAC and HVA were decreased about 10-fold in the rotenone-treated responder brain (Figure 4). These findings are similar to what has been reported in other studies in rats, after an intracerebral injection of rotenone into the MFB [31] and after intracerebral 6-OHDA injection [32,33]. As no changes in formation rate constants of DOPAC and HVA (k46 and k58 for DOPAC, and k47 and k59 for HVA; see Table 1) were found in the rotenone-treated responder relative to the control cerebral hemisphere, a decrease in baseline concentrations results solely from increased elimination rate constants for DOPAC and HVA.

\section{DOPAC and HVA following administration of L-DOPA}

Following L-DOPA administration, differences were found in DOPAC and HVA concentrations and in rate 


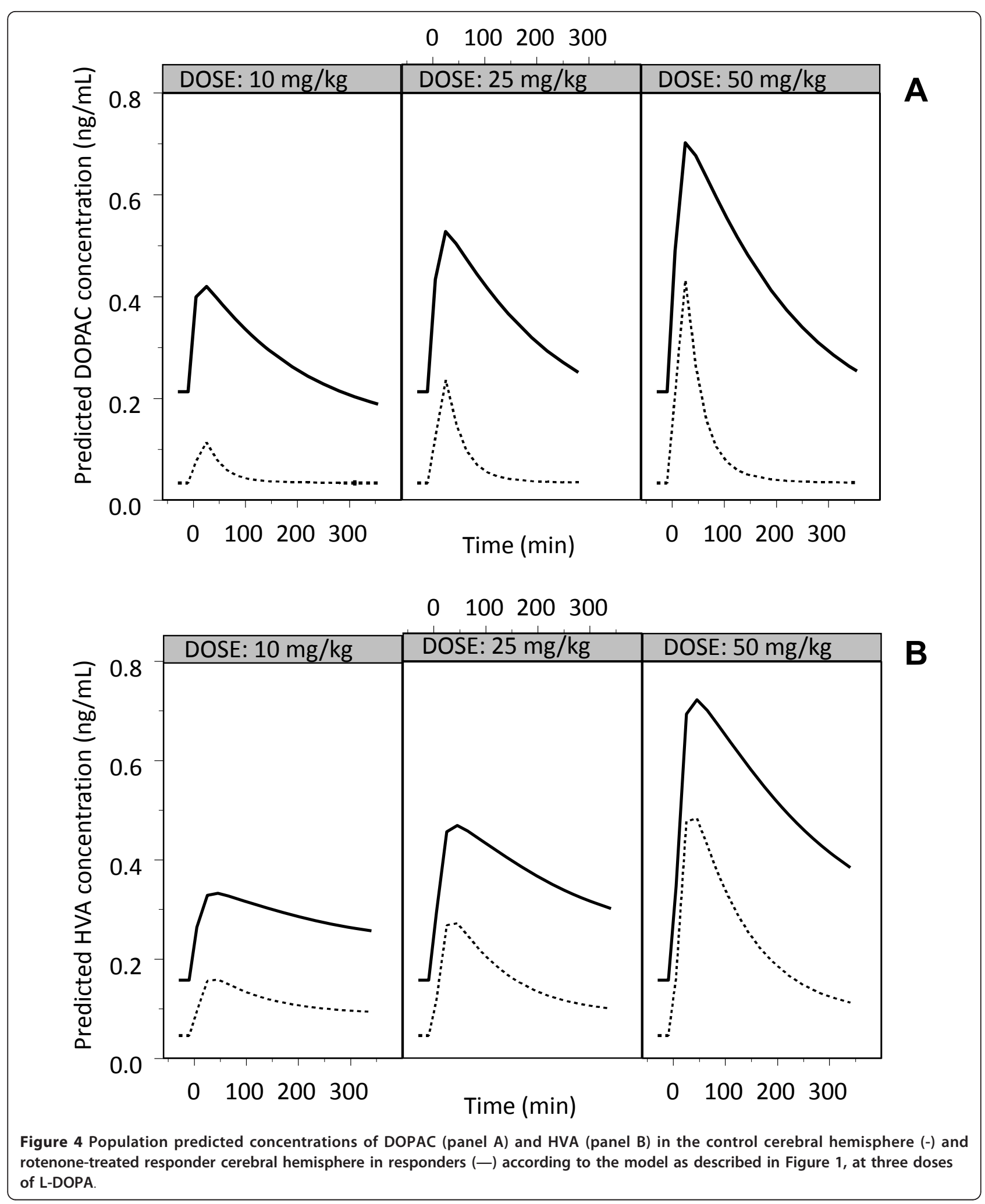




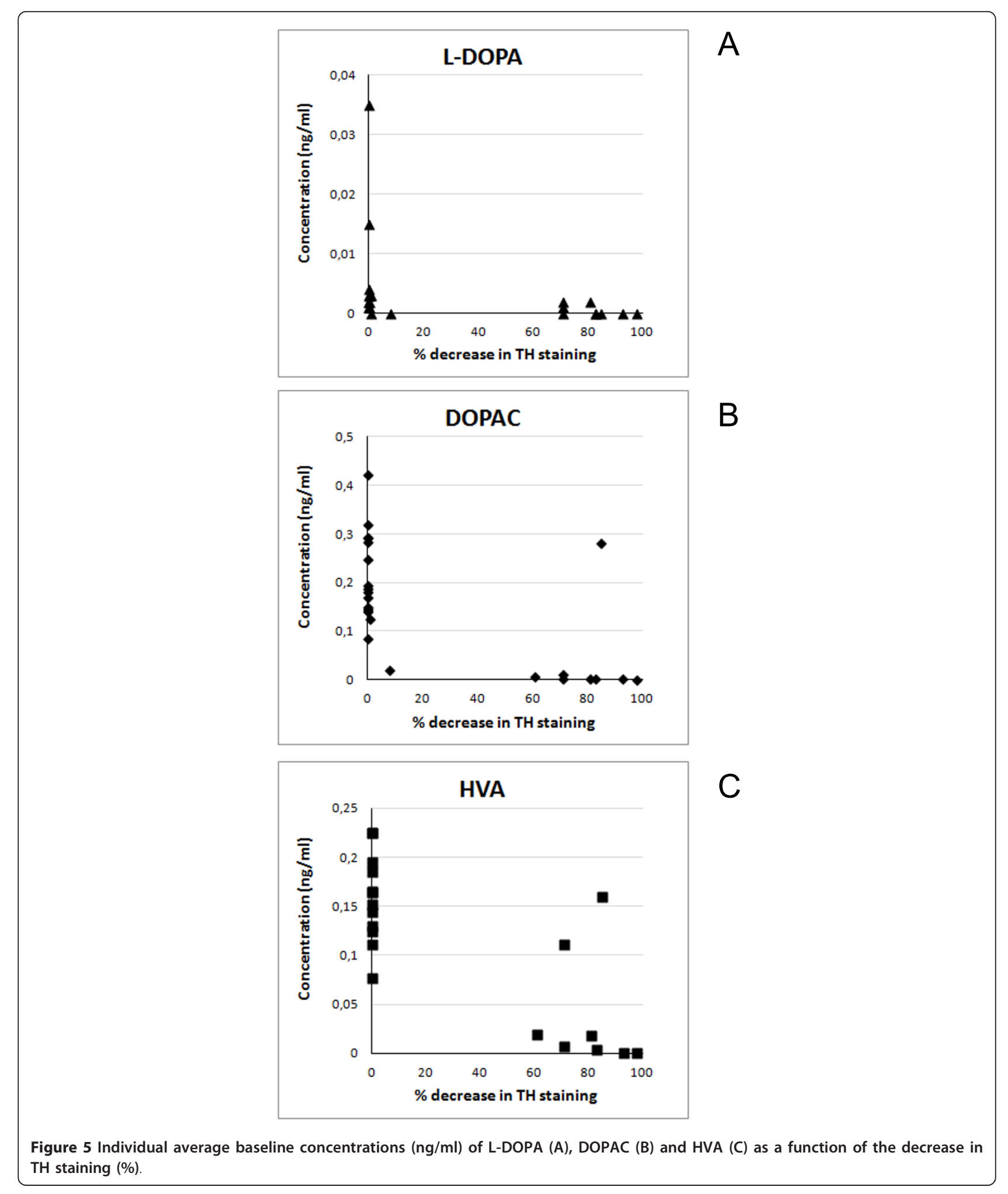


constants for elimination. In our model, the metabolism from dopamine to DOPAC and HVA was explained by first-order kinetics (Figure 1, Table 1), as in the model previously developed $[25,26]$. Following L-DOPA administration, for DOPAC the elimination rate constant in the rotenone-treated responder cerebral hemisphere $\left(0.038 \mathrm{~min}^{-1}\right)$ was increased about 7 -fold compared with the elimination rate constant in the control side $\left(0.0053 \mathrm{~min}^{-1}\right)$. For HVA this diseaseinduced increase was about a factor $2.5\left(0.011 \mathrm{~min}^{-1}\right.$ for the rotenone-treated responder and $0.0044 \mathrm{~min}^{-1}$ for the control cerebral hemisphere). With unchanged values for the formation rate constants (k46 and $k 58$ for DOPAC, and k47 and k59 for HVA; see Table 1) and lower baseline concentrations measured for both DOPAC and HVA, the higher elimination rate constant as found for DOPAC and HVA would be possible if dopamine concentrations were lower in the rotenone-treated responder cerebral hemisphere such that metabolite formation rate-dependent elimination occurs. This is also called "flip-flop kinetics" [34], i.e. [metabolite formation rate constant $x$ amount of metabolite remaining to be formed] is about equal to the [metabolite elimination rate constant $x$ amount of metabolite remaining to be eliminated]). Reduced dopamine concentrations in the rotenone-treated responder cerebral hemisphere are indeed plausible with a diminished amount of dopaminergic neurons as indicated by substantially decreased $\mathrm{TH}$ staining.

A number of processes may contribute to the elimination of DOPAC and HVA from the brain. Elimination of DOPAC may occur by conjugation, in rats mostly to sulphates [35], or by transformation to HVA by catechol-O-methyltransferase. For HVA, formed as metabolite of DOPAC but also directly from dopamine [36-38], the mechanisms of elimination from the brain are not fully clear. HVA may leave the brain by passive diffusion [38]. Also, HVA leaves the brain via a probenecid-sensitive organic anion transport (OAT3) system, present at the BBB [39]. This HVA efflux transport system is likely to play an important role in controlling the level of HVA in the brain. An apparent in vivo efflux rate constant of HVA from the brain was determined by Mori et al. [36] and found to be $0.017 \mathrm{~min}^{-1}$. Our value for the elimination rate constant of HVA in the control cerebral hemisphere was $0.044 \mathrm{~min}^{-1}$ and of the same order of magnitude.

Although the expression of OATs is affected (mainly down-regulated) in certain renal and hepatic diseases [40], to our knowledge, no studies have been performed indicating changes in OAT functionality at the $\mathrm{BBB}$. The increased values that we found for the elimination rate constants for DOPAC and HVA could have been the result of up-regulation of one or more of active elimination processes that we are not yet able to specify.

In general, the integrated approach used in this study, including plasma pharmacokinetics, BBB transport and in vivo assessment of dopamine system functionality at different stages of the disease may help to unravel more mechanistically the factors that play a role in effective Parkinson's disease treatment.

\section{Conclusions}

The developed population pharmacokinetic model allowed the integration of the kinetics of L-DOPA and its conversion to DOPAC and HVA in both control and rotenone-treated responder brain. It was demonstrated that 2 weeks following a unilateral infusion of rotenone into the rat brain, dopamine depletion resulted in lower brain levels and higher elimination rates of DOPAC and HVA for the diseased cerebral hemisphere. This was, however, not accompanied by changes in the plasma pharmacokinetics and BBB transport of L-DOPA. Taken together, the varying results on whether or not changes in BBB transport in Parkinson's disease in previous studies and in this study indicate that changes in BBB functionality are not specifically associated with Parkinson's disease, and therefore cannot account for the decreased benefit of L-DOPA at later stages of Parkinson's disease.

\section{List of abbreviations}

BBB: blood-brain barrier; DOPAC: 3,4-dihydroxyphenylacetic acid; HVA: homovanillic acid; L-DOPA: 3,4-dihydroxy-L-phenylalanine; TH: tyrosine hydroxylase; MFB: medial forebrain bundle.

\section{Acknowledgements}

The authors would like to acknowledge Mark A Ward (Eli Lilly \& Co. Ltd.) for the technical assistance in the immunostaining of the brains and Margret Blom for the technical assistance in the HPLC analysis of the plasma samples. The described work was financially supported by Lilly Development Centre, Mont-Saint-Guibert, Belgium.

\section{Author details}

'Division of Pharmacology, LACDR Leiden University, Leiden, The Netherlands. ${ }^{2}$ LAP\&P Consultants BV, Leiden, The Netherlands.

${ }^{3}$ Neurodegenerative Diseases Drug Hunting Team, Eli Lilly \& Co Ltd., Windlesham, UK. 'LACDR/Pharmacology, Gorlaeus Laboratories, Leiden University, Einsteinweg 55, 2333 CC, Leiden, The Netherlands.

\section{Authors' contributions}

PR carried out the experiments, modelling of the data and contributed to writing of the manuscript, HD contributed to the model development and writing of the manuscript, $\mathrm{MO}$ contributed to the staining of the brain tissues, interpretation of the data and writing of the manuscript, MD participated in the design of the study and revision of the manuscript, EL conceived the project of which this study was a part of, participated in design and coordination of the study, and contributed to writing of the manuscript. All authors have read and approved the final version of the manuscript.

\section{Competing interests}

The authors declare that they have no competing interests.

Received: 20 November 2011 Accepted: 8 February 2012 Published: 8 February 2012 


\section{References}

1. Elsworth JD, Roth RH: Dopamine synthesis, uptake, metabolism, and receptors: relevance to gene therapy of Parkinson's disease. Exp Neurol 1997, 144:4-9

2. Westerink $\mathrm{BH}$ : Sequence and significance of dopamine metabolism in the rat brain. Neurochem Int 1985, 7:221-227.

3. Männistö PT, Ulmanen I, Lundström K, Taskinen J, Tenhunen J, Tilgmann C, Kaakkola S: Characteristics of catechol O-methyl-transferase (COMT) and properties of selective COMT inhibitors. Prog Drug Res 1992, 39:291-350.

4. Dauer W, Przedborski S: Parkinson's disease: mechanisms and models. Neuron 2003, 39:889-909.

5. Deleu D, Northway MG, Hanssens Y: Clinical pharmacokinetic and pharmacodynamic properties of drugs used in the treatment of Parkinson's disease. Clin Pharmacokinet 2002, 41:261-309.

6. Obeso JA, Rodriguez-Oroz M, Marin C, Alonso F, Zamarbide I, Lanciego JL, Rodriguez-Diaz M: The origin of motor fluctuations in Parkinson's disease: importance of dopaminergic innervation and basal ganglia circuits. Neurology 2004, 62:S17-S30.

7. Nyholm D: Pharmacokinetic optimisation in the treatment of Parkinson's disease: an update. Clin Pharmacokinet 2006, 45:109-136.

8. Bhidayasiri R, Truong DD: Motor complications in Parkinson disease: clinical manifestations and management. J Neurol Sci 2008, 266:204-215.

9. Factor SA: Current status of symptomatic medical therapy in Parkinson's disease. Neurotherapeutics 2008, 5:164-180

10. Abbott NJ, Patabendige AA, Dolman DE, Yusof SR, Begley DJ: Structure and function of the blood-brain barrier. Neurobiol Dis 2010, 37:13-25.

11. Carvey PM, Zhao CH, Hendey B, Lum H, Trachtenberg J, Desai BS, Snyder J Zhu YG, Ling ZD: 6-Hydroxydopamine-induced alterations in blood-brain barrier permeability. Eur J Neurosci 2005, 22:1158-1168.

12. Bartels $A L$, van Berckel $B N$, Lubberink $M$, Luurtsema $G$, Lammertsma $A A$, Leenders $\mathrm{KL}$ : Blood-brain barrier P-glycoprotein function is not impaired in early Parkinson's disease. Parkinsonism Relat Disord 2008, 14:505-508.

13. Bartels AL, Willemsen AT, Kortekaas R, de Jong BM, de Vries R, de Klerk O, van Oostrom JC, Portman A, Leenders KL: Decreased blood-brain barrier P-glycoprotein function in the progression of Parkinson's disease, PSP and MSA. J Neural Transm 2008, 115:1001-1009.

14. Ravenstijn PG, Merlini M, Hameetman M, Murray TK, Ward MA, Lewis $H$, Ball G, Mottart C, de Ville DG, Lemarchand T, van Belle K, O'Neill MJ, Danhof $M$, de Lange EC: The exploration of rotenone as a toxin for inducing Parkinson's disease in rats, for application in BBB transport and PK-PD experiments. J Pharmacol Toxicol Meth 2008, 57:114-130.

15. Astradsson A, Jenkins BG, Choi JK, Hallett PJ, Levesque MA, McDowell JS, Brownell $\mathrm{AL}$, Spealman RD, Isacson O: The blood-brain barrier is intact after levodopa-induced dyskinesias in Parkinsonian primates-evidence from in vivo neuroimaging studies. Neurobiol Dis 2009, 35:348-351.

16. del Amo EM, Urtti A, Yliperttula M: Pharmacokinetic role of L-type amino acid transporters LAT1 and LAT2. Eur J Pharm Sci 2008, 35:161-174.

17. Ohtsuki S, Yamaguchi H, Kang YS, Hori S, Terasaki T: Reduction of L-type amino acid transporter 1 mRNA expression in brain capillaries in a mouse model of Parkinson's disease. Biol Pharm Bull 2010, 33:1250-1252.

18. Westin JE, Lindgren HS, Gardi J, Nyengaard JR, Brundin P, Mohapel P, Cenci MA: Endothelial proliferation and increased blood-brain barrier permeability in the basal ganglia in a rat model of 3,4-dihydroxyphenylL-alanine-induced dyskinesia. J Neurosci 2006, 26:9448-9461.

19. Alexander GM, Schwartzman RJ, Grothusen JR, Gordon SW: Effect of plasma levels of large neutral amino acids and degree of parkinsonism on the blood-to-brain transport of levodopa in naive and MPTP Parkinsonian monkeys. Neurology 1994, 44:1491-1499.

20. De Lange EC, de Boer BA, Breimer DD: Microdialysis for pharmacokinetic analysis of drug transport to the brain. Adv Drug Deliv Rev 1999, 36:211-227.

21. Paxinos G, Watson C, Pennisi M, Topple A: Bregma, lambda and the interaural midpoint in stereotaxic surgery with rats of different sex strain and weight. J Neurosci Meth 1985, 13:139-143.

22. Nutt JG, Woodward WR, Hammerstad JP, Carter JH, Anderson JL: The "onoff" phenomenon in Parkinson's disease. Relation to levodopa absorption and transport. N Eng J Med 1984, 310:483-488.

23. Moghaddam B, Bunney BS: Ionic composition of microdialysis perfusing solution alters the pharmacological responsiveness and basal outflow of striatal dopamine. J Neurochem 1989, 53:652-654.
24. Doller HJ, Connor JD, Lock DR, Sloviter RS, Dvorchik BH, Vesell ES: Levodopa pharmacokinetics. Alterations after benserazide, a decarboxylase inhibitor. Drug Metab Dispos 1978, 6:164-168.

25. Sato S, Koitabashi T, Koshiro A: Pharmacokinetic and pharmacodynamic studies of L-dopa in rats. I. Pharmacokinetic analysis of L-dopa in rat plasma and striatum. Biol Pharm Bull 1994, 17:1616-1621.

26. Sato $S$, Koitabashi T, Koshiro A: Pharmacokinetic and pharmacodynamic studies of L-dopa in rats. II. Effect of L-dopa on dopamine and dopamine metabolite concentration in rat striatum. Biol Pharm Bull 1994, 17:1622-1629.

27. Pifl C, Hornykiewicz O: Dopamine turnover is upregulated in the caudate/ putamen of asymptomatic MPTP-treated rhesus monkeys. Neurochem Int 2006, 49:519-524.

28. Rose S, Nomoto M, Kelly E, Kilpatrick G, Jenner P, Marsden CD: Increased caudate dopamine turnover may contribute to the recovery of motor function in marmosets treated with the dopaminergic neurotoxin MPTP. Neurosci Lett 1989, 101:305-310

29. Miwa S, Gillberg PG, Bjurling P, Yumoto N, Odano I, Watanabe Y, Långström B: Assessment of dopamine and its metabolites in the intracellular and extracellular compartments of the rat striatum after peripheral administration of L-[11C]dopa. Brain Res 1992, 578:122-128.

30. DeJesus OT, Haaparanta M, Solin O, Nickles RJ: 6-fluoroDOPA metabolism in rat striatum: time course of extracellular metabolites. Brain Res 2000 877:31-36

31. Antkiewicz-Michaluk L, Wardas J, Michaluk J, Romaska I, Bojarski A Vetulani J: Protective effect of 1-methyl-1,2,3,4-tetrahydroisoquinoline against dopaminergic neurodegeneration in the extrapyramidal structures produced by intracerebral injection of rotenone. Int J Neuropsychopharmacol 2004, 7:155-163.

32. Sarre S, Herregodts P, Deleu D, Devrieze A, De Klippel N, Ebinger G, Michotte $Y$ : Biotransformation of L-dopa in striatum and substantia nigra of rats with a unilateral, nigrostriatal lesion: a microdialysis study. Naunyn Schmiedebergs Arch Pharmacol 1992, 346:277-285.

33. Brannan T, Bhardwaj A, Martinez-Tica J, Weinberger J, Yahr M: Striatal Ldopa metabolism studied in vivo in rats with nigrostriatal lesions. $J$ Neural Transm Park Dis Dement Sect 1990, 2:15-22.

34. Rowland M, Tozer TN: Extravascular Dose. In Clinical PharmacokineticsConcepts and Applications. Edited by: Balado D. Media, PA: Williams 1995:34-50.

35. Swahn CG, Wiesel FA: Determination of conjugated monoamine metabolites in brain tissue. J Neural Transm 1976, 39:281-290.

36. Westerink $B H$, de Vries JB: On the origin of dopamine and its metabolite in predominantly noradrenergic innervated brain areas. Brain Res 1985 , 330:164-166

37. Wood PL, Altar CA: Dopamine release in vivo from nigrostriatal, mesolimbic, and mesocortical neurons: utility of 3-methoxytyramine measurements. Pharmacol Rev 1988, 40:163-187.

38. Amin F, Davidson M, Davis KL: Homovanillic acid measurement in clinical research: a review of methodology. Schizophr Bull 1992, 18:123-148.

39. Mori S, Takanaga H, Ohtsuki S, Deguchi T, Kang YS, Hosoya K, Terasaki T: Rat organic anion transporter 3 (rOAT3) is responsible for brain-to-blood efflux of homovanillic acid at the abluminal membrane of brain capillary endothelial cells. J Cereb Blood Flow Metab 2003, 23:432-440.

40. Anzai N, Kanai $Y$, Endou H: Organic anion transporter family: current knowledge. J Pharmacol Sci 2006, 100:411-426.

doi:10.1186/2045-8118-9-4

Cite this article as: Ravenstijn et al:: Evaluation of blood-brain barrier transport and CNS drug metabolism in diseased and control brain after intravenous L-DOPA in a unilateral rat model of Parkinson's disease. Fluids and Barriers of the CNS 2012 9:4. 